\title{
Performance of Slurry Shield Tunnelling in Mixed Strata Based on Field Measurement and Numerical Simulation
}

\author{
Jian Cui $\mathbb{D}^{D}$, Wang-Hao Xu, Yong Fang ${ }^{\mathbb{D}}$, Li-Ming Tao ${ }^{D}$, and Chuan He \\ Key Laboratory of Transportation Tunnel Engineering (Southwest Jiaotong University), Ministry of Education, Chengdu, China \\ Correspondence should be addressed to Yong Fang; fy980220@swjtu.cn
}

Received 22 October 2019; Accepted 9 December 2019; Published 8 January 2020

Academic Editor: Carlo Santulli

Copyright (c) 2020 Jian Cui et al. This is an open access article distributed under the Creative Commons Attribution License, which permits unrestricted use, distribution, and reproduction in any medium, provided the original work is properly cited.

\begin{abstract}
There are severe challenges for slurry pressure balance tunnel boring machine (TBM) tunnelling in sandy cobble soil of Beijing, Chengdu, and Lanzhou in China. And the problems caused by tunnelling from silty clay to sandy cobble stratum are more serious. With the change of stratum, the key parameters and surface settlement will change correspondingly. Controlling the key parameters and predicting the surface settlement accurately and efficiently is important for hazard mitigation and risk management. In this study, based on the Tsinghuayuan Tunnel project in Beijing, the key parameters and surface settlement while tunnelling from silty clay to sandy cobble stratum are studied. Firstly, the difference of key parameters while tunnelling in two different strata is analyzed. The analysis shows that immediate responses to changes in the stratum are recommended in order to ensure construction efficiency. Then, a refined 3D finite difference model is developed to simulate the slurry TBM tunnelling in different strata. For refined simulation, three key parameters obtained from measurement data were applied to the 3D models, and the simulation results were compared with the field data. Results show that the refined model has good performance in terms of the accuracy and efficiency. This study provides a good engineering practice reference for slurry TBM tunnelling in mixed strata.
\end{abstract}

\section{Introduction}

With the development and utilization of urban underground space, new high-speed railway lines in cities are created using tunnel excavation schemes, especially in an international metropolis like Beijing. In particular, shield tunnelling methods are used in a large number of urban tunnels due to their advantages of environmental protection, safety, and reliability of construction and relatively small impact on ground traffic [1]. The control of surface settlement caused by tunnelling is particularly important in the complex urban environment, and the harm caused by ground disturbance cannot be ignored [2-6].

Controlling the key parameters well can effectively reduce surface settlement caused by shield construction [711]. These parameters mainly include cutterhead rotational speed, shield tunnelling speed, cutterhead torque, shield thrust, slurry pressure, and grouting pressure. When tunnelling in two or more different strata, differences in key parameters will become more pronounced, and the working state of the shield machine will also change significantly.
Under different geological conditions, the torque and thrust required by shield are quite different, and the corresponding surface settlement will also be different. Lin et al. [12] and Zheng et al. [13] discussed the influence of shield key parameters on the surface settlement. Li et al. [14] studied the control of the key parameters of the slurry shield under the Yellow River in the rough sand and gravel strata.

At present, many scholars have analyzed and studied tunnelling performance under different geological conditions $[3,15,16]$. Zhao et al. [17] conducted a case history of tunnelling through frequently changing and mixed ground in Singapore. Chen et al. [18] monitored the Hangzhou subway to study the development of excess pore water pressure, soil settlement, and horizontal displacement of the soil with shield tunnelling. Jung et al. [19] conducted a case study on tunnel tunnelling through the Han River. Wongsaroj et al. [20] investigated the effect of TBM driving parameters on ground surface movements. Hassanpour et al. [21] made a comparative analysis of the predicted parameters, measured the data of different tunnelling parameter prediction models, and studied the relationship between tunnelling parameters and 
rock mass parameters and then fitted a new mathematical model. In the shield tunnelling project of the Shanghai M8 subway line, Zhu et al. [22] obtained the numerical curves of the simulated parameters under the conditions of different cover depths and cutter plate opening rate through a model test and then created the mathematical model and variation rules of the tunnelling parameters through the fitting and analysis of the test results. Song and Sun [23] constructed the fitting model of the torque, total thrust, and each rotation of the cutterhead, which improved the tunnelling efficiency. Wei et al. [24] studied the relations between EPB shield parameters and conducted a test to study the influence on ground deformation by shield parameters. He et al. [3] studied the soil disturbance caused by shield tunnelling in complex interbed strata using field test, model test, and particle distinct element method. With the rapid development of computer technology, numerical simulation methods are applied to study the surface settlement caused by tunnel excavation [25-33]. Rohola et al. [34] considered the un-uniform gap and established a TBM complete model with FLAC3D and studied the rule of LDP variation at different reference points on the circumference of the tunnel and the contact force characteristics of the shield. Liu et al. [35] studied the influence of tunnel excavation on adjacent single pile and pile foundation with ABAQUS finite element software, taking the Shanghai metro line 3 project as the background, and most of the relevant factors in tunnelling are taken into consideration including slurry pressure, grouting pressure, grouting material hardening, and soil-pile interaction. Zhang et al. [36] performed three-dimensional finite element analysis for URUP to observe the ground settlement and lateral displacement due to twin-tunnel excavation in silty clay, and a critical cover depth of $0.55 D$ is proposed for the URUP method below which value instability and collapse of surrounding soils will be highly likely. Michael et al. [31] studied the effects of slurry TBM operational parameters on ground deformation by analyzing field data and computational modelling, and the results quantify the importance of the various pressures on controlling ground deformation. In this study, two 3D models were conducted to simulate the slurry pressure balanced (SPB) TBM tunnelling from silty clay to complex interbed strata, and the parameters, namely, thrust reaction, slurry pressure, and grouting pressure, obtained from field data were applied to the models.

Although many scholars have conducted analysis and research on tunnelling in different strata, tunnel construction is extremely sensitive to variation in soil parameters. Different types of shield machines are used under different geological conditions, and their tunnelling performance is also quite different. Any given study can provide a reference for other shield construction in the same area only when local layer conditions and shield machine types and sizes are similar. Therefore, it is still necessary to analyze the variation of driving parameters and ground disturbance during the tunnelling process for different shield types and geological conditions. In this study, based on the SPB tunnelling practice of Tsinghuayuan Tunnel in Beijing, key parameters from measurement data are analyzed and compared while tunnelling in silty clay stratum and sandy cobble stratum, and then a refined $3 \mathrm{D}$ finite difference model is developed to investigate the surface settlement. The simulation results were then compared against the field data. A comparison of the different types of surface settlement while tunnelling in silty clay stratum and sandy cobble stratum and the reasons for the differences are then presented. Finally, a series of parametric analysis are conducted to give some suggestions for controlling the surface settlement.

\section{Project Overview}

Tsinghuayuan Tunnel of the Beijing-Zhangjiakou High Speed Railway is located in a prosperous central area of Beijing. It is a key aspect of the 2020 Beijing-Zhangjiakou Winter Olympics affiliated project. An overview of the tunnel is shown in Figure 1. The tunnel is close to the Beijing Metro Line 13 and passes through 3 subways, 6 major municipal roads, and about 106 important municipal pipelines. There are numerous buildings around the tunnel. Due to the excavation of the tunnel, there is a high risk of hidden dangers in the surrounding environment. Therefore, it is necessary to analyze the project in the context of this complex environment.

The length of the main tunnel is $6.02 \mathrm{~km}$ as shown in Figure 1. The shield section is divided into two sections: the $2 \# \sim 1 \#$ section is $2707.5 \mathrm{~m}$ long and the $3 \# \sim 2 \#$ section is $1741 \mathrm{~m}$ long. The shield has an inner diameter of $11.10 \mathrm{~m}$, an outer diameter of $12.20 \mathrm{~m}$, and a shield cutterhead diameter of $12.64 \mathrm{~m}$. The tunnel is constructed with the $\Phi 12.64 \mathrm{~m} \mathrm{SPB}$ TBM manufactured by Herrenknecht, Germany. The length of the shield body is about $14 \mathrm{~m}$, and the full prefabricated lining segment $6+2+1$ mode is used for assembly. The lining of each ring is $2 \mathrm{~m}$ long, and the thickness of the lining segment is $0.55 \mathrm{~m}$. The maximum designed tunnelling speed of the shield machine is $60 \mathrm{~mm} / \mathrm{min}$, and the maximum thrust and torque are $160850 \mathrm{kN}$ and $26118 \mathrm{kN} \cdot \mathrm{m}$, respectively. The shield cutterhead has a spoke panel structure, as shown In Figure 2. The opening ratio of the cutterhead is about $36 \%$, and the maximum opening size (the maximum allowable particle diameter) is about $96 \mathrm{~cm}$. This study mainly analyzes the tunnelling sections from the 1st to the 447 th ring of the $3 \# \sim 2 \#$ shield section.

\section{Engineering Geological Characteristics}

Beijing is located in the northern section of the North China Plain. The tunnel project is located in the Haidian District, in the northwest of the Beijing Plain. The ground elevation is $48.5 \mathrm{~m} \sim 51.0 \mathrm{~m}$, and the terrain is flat. The inner strata of the project mainly contain silty clay, silt, fine sand, coarse sand, and pebble soil. Relatively speaking, silt and silty clay have better self-stability, while sand soil and pebble soil have poor self-stability and are prone to collapse. The crossing geology of the shield tunnel mainly includes silty clay, silt, gravel, and pebble soil. The geological conditions of the $3 \# \sim 2 \#$ shield section is complex and variable: the area of the $3 \#$ launching shaft is shallow buried and the whole excavation section is silty clay. With the excavation of the shield tunnel, the cover depth increases, and the geology of the excavation section changes. The soil layer gradually becomes an interbedded 


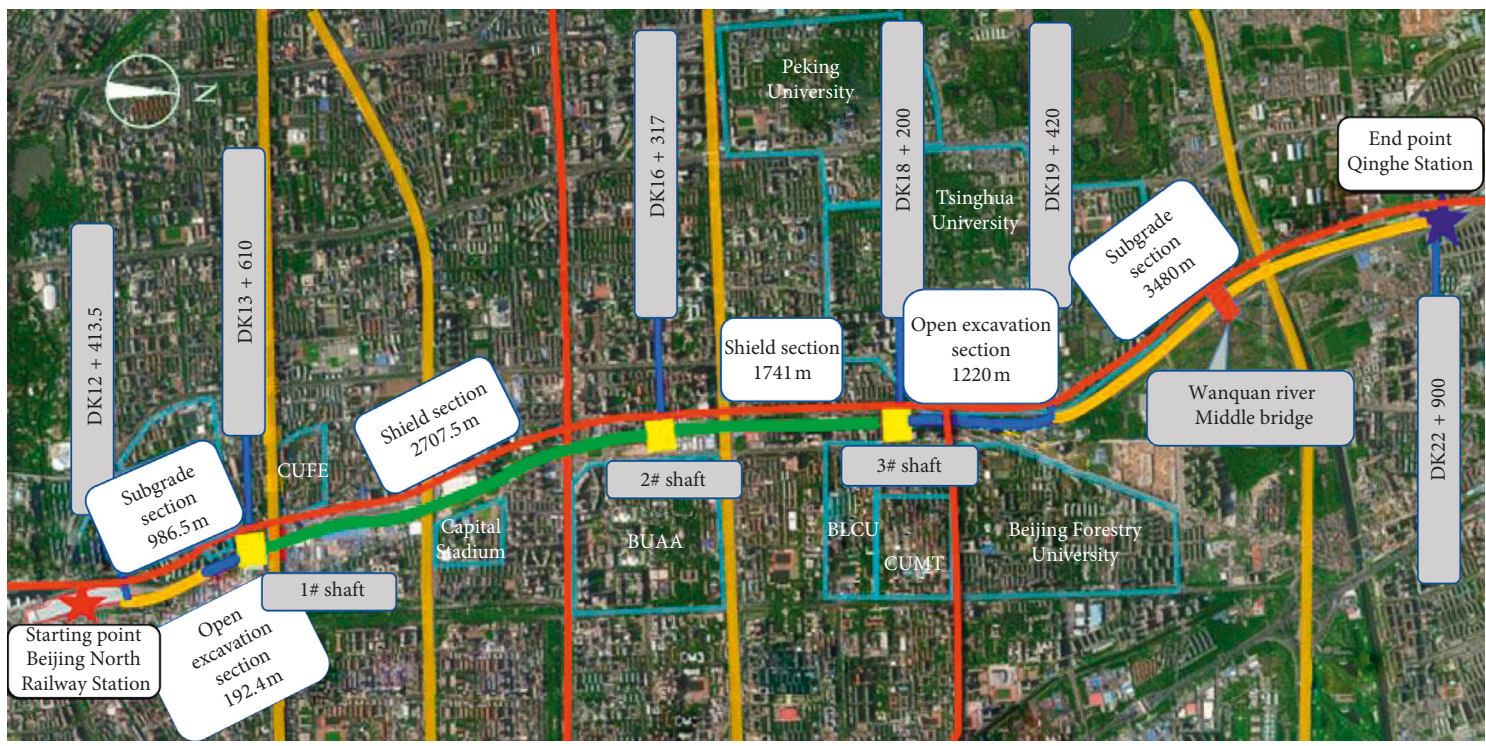

FIgure 1: Overview of the Tsinghuayuan Tunnel project.

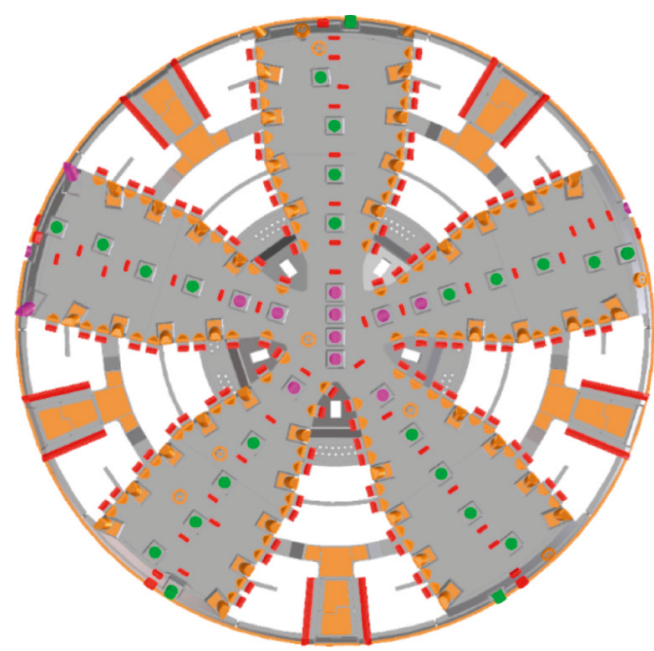

FIgURE 2: Schematic diagram of shield cutterhead.

structure of pebble soil, sand, and silty clay. The pebble soil accounts for more than half of the total, which is a typical "soft and hard" strata. The geological section of the shield section (1st ring to 447 th ring) of the study section is shown in Figure 3. The excavation section of the 1st to 225th ring is basically silty clay, while the excavation section of the 225 th to 447 th ring is basically complex interbed strata, namely, sandy cobble and silty clay.

\section{Tunnelling Key Parameters of Shield Tunnelling}

The selection and control of tunnelling key parameters is especially difficult, and the reasonable selection and control of key parameters are of vital importance to tunnelling efficiency, tool wear control, cutterhead protection, and surface settlement control. In short, control of the tunnelling parameters of the shield machine in the sandy cobble stratum is regarded as one of the key points of safe and rapid tunnelling. In this study, the key parameters of shield tunnelling are statistically analyzed based on the range from 1 to 447 rings of the $3 \# \sim 2 \#$ shield section.

4.1. Cutterhead Rotational Speed and Tunnelling Speed. The rotational speed of the cutterhead and the tunnelling speed of the shield machine directly reflect efficiency while tunnelling in the soil stratum. Figures 4 and 5 illustrate the history of the rotational speed of the cutterhead and the tunnelling speed of the shield machine. The rotation speed is basically about $1.2 \mathrm{rpm}$ under two geological conditions. It is obvious that there is a significant salient section at the junction of the two strata, which shows that key parameters should be adjusted to adapt to the change of strata. The influencing factors of the cutterhead rotational speed are more related to the manual control of the shield machine. Therefore, it is sufficient to show that the shield constructors are skilled in the operation of the shield machine and ensure that the shield machine has a stable blade speed so that when it passes through the risk source, the speed of the cutter disk remains consistent and the balance of the construction is maintained.

The shield tunnelling speed in Figure 5 is different from the cutterhead rotational speed. Under two different geological conditions, the shield tunnelling speed has a certain difference. In the initial silty clay section, the average of shield tunnelling speed is $20.49 \mathrm{~mm} / \mathrm{min}$, while in the sandy cobble stratum, it is $18.23 \mathrm{~mm} / \mathrm{min}$, the tunnelling speed decreased, and the rate of change was $11.03 \%$. Appropriate reduction of tunnelling speed enables the cutterhead to fully break the harder bottom layer, which effectively reduces the wear of the larger pebbles on the cutter disk. The tunnelling speed of the shield in the silty clay section is faster than that in the sandy cobble section, and the variation range is smaller than those for the shield thrust and the cutterhead torque (the shield thrust and the cutterhead torque are introduced below). 


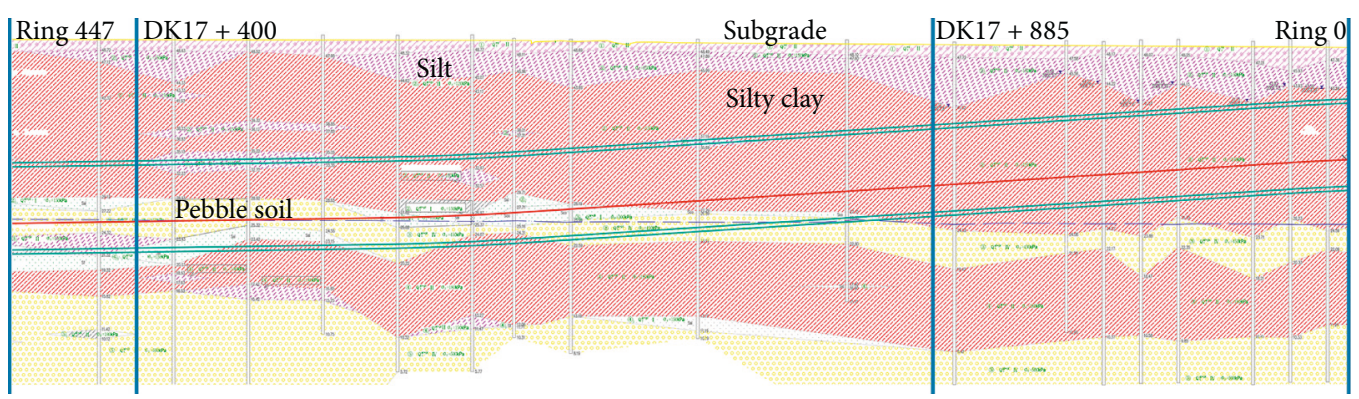

FIGURE 3: Geological profile of the 0-447 rings.

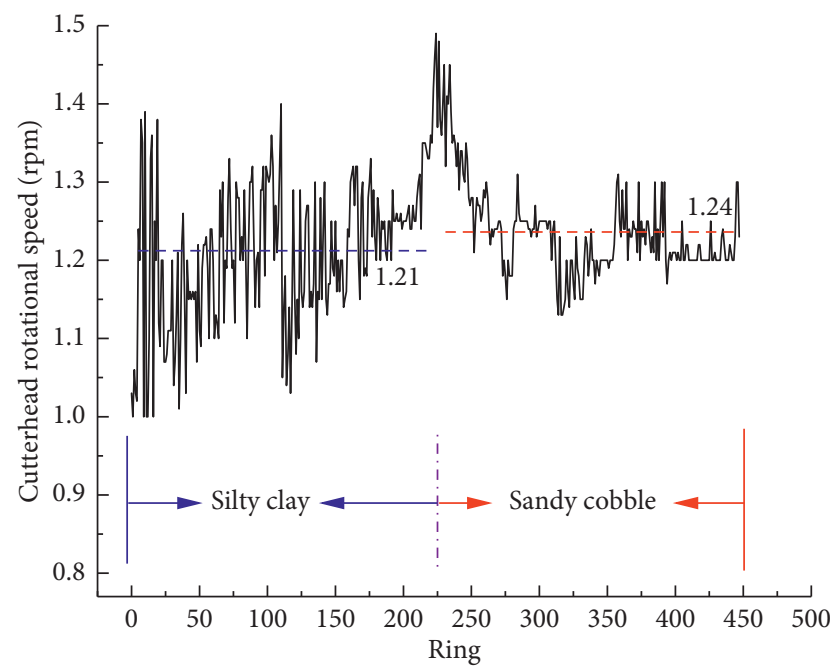

FIGURE 4: History of rotational speed of cutterhead.

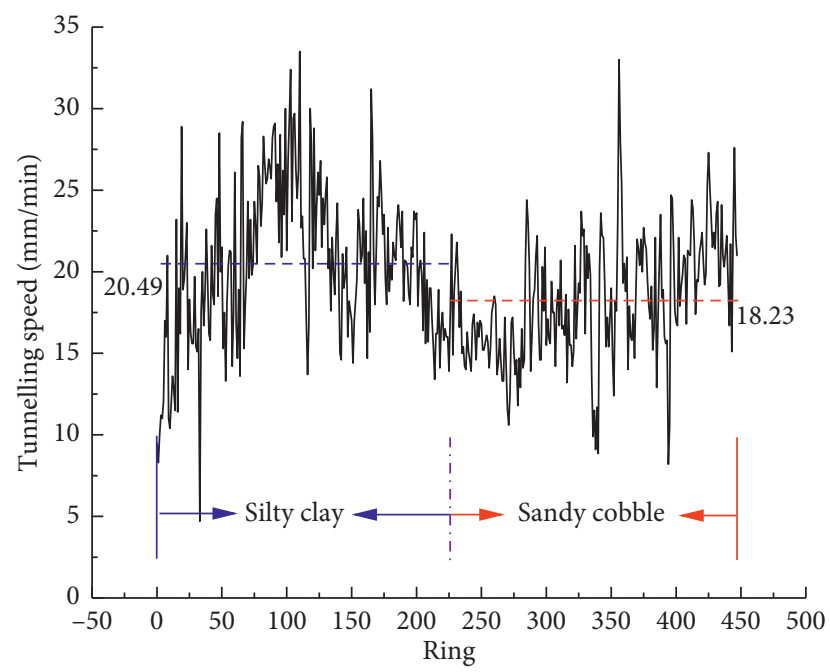

FIGURE 5: History of shield tunnelling speed.

4.2. Torque and Thrust. The torque while tunnelling in the soil generally includes the resistance torque of the cutting soil, the rotational resistance torque of the cutterhead, the counter torque generated by the thrust of the cutterhead, the friction torque generated by the sealing device, the friction torque of the front surface of the cutterhead, the friction torque behind the cutterhead, the shear torque of the cutterhead opening, and the agitation moment in the earth pressure. This study mainly studies the variation in the cutterhead torque of a shield tunnelling machine when the stratum changes. Figure 6 shows the history of the cutterhead torque. In different geological conditions, the average torque of the cutterhead increased from $5.75 \mathrm{MN} \cdot \mathrm{m}$ in the silty clay stratum to $8.42 \mathrm{MN} \cdot \mathrm{m}$ in the sandy cobble stratum, with a growth rate of approximately $46.43 \%$. Based on the previous analysis of the rotational speed and tunnelling speed of the shield, the change rate of the rotational speed and tunnelling speed is relatively low, while the growth rate of the shield torque is about $46.43 \%$, which is relatively large. Therefore, it can be considered that the increase in torque is mainly caused by the changes in geological conditions, rather than personnel operations during shield tunnelling. When tunnelling in the sandy cobble stratum, as the physical and mechanical parameters of the stratum become more complicated and the number of pebbles increases, the resistance the cutter needs to overcome to destroy the surrounding rock layer increases, which leads to a significant increase in the torque required by the cutterhead in tunnelling.

Figure 7 shows the bar distribution of torque. It can be seen from the variation diagram of the torque in Figure 7 that not only the mean value of the shield torque but also the fluctuation range of the torque increases under different geological conditions. The fluctuation of cutterhead torque in the sandy cobble stratum is more discrete than that in the silty clay. It can be seen from Figure 7 that the torque distribution is narrower in the silty clay stratum and wider in the sandy cobble stratum, and the torque is more discrete in the sandy cobble stratum. The standard deviation of torque is $0.79 \mathrm{MN} \cdot \mathrm{m}$ in the silty clay stratum and $1.25 \mathrm{MN} \cdot \mathrm{m}$ in the sandy cobble stratum.

The main factors affecting the shield thrust are the friction between the shield shell and the soil, the resistance of the working face, the resistance of cutting into soil, and the frictional resistance of the lining segment and the shield tail. This study mainly studies the change of thrust of the shield tunnelling machine when the stratum changes. Figure 8 shows the history of the thrust along with the shield tunnelling. In different geological conditions, the average of the shield thrust increased from $33632 \mathrm{kN}$ in the silty clay to $48586 \mathrm{kN}$ in the sandy cobble stratum, for a growth rate of approximately $44.46 \%$. Since the shield operation is basically 


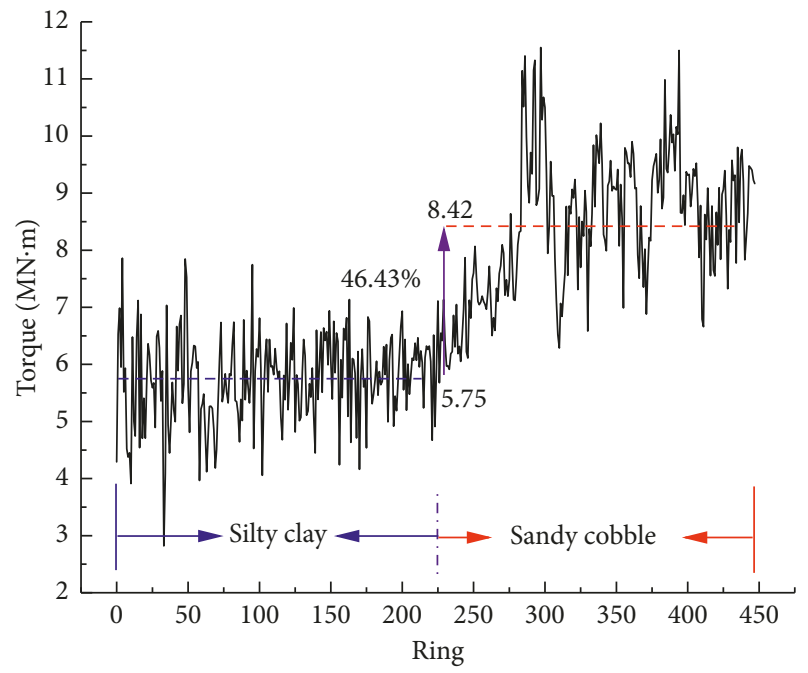

Figure 6: History of cutterhead torque.

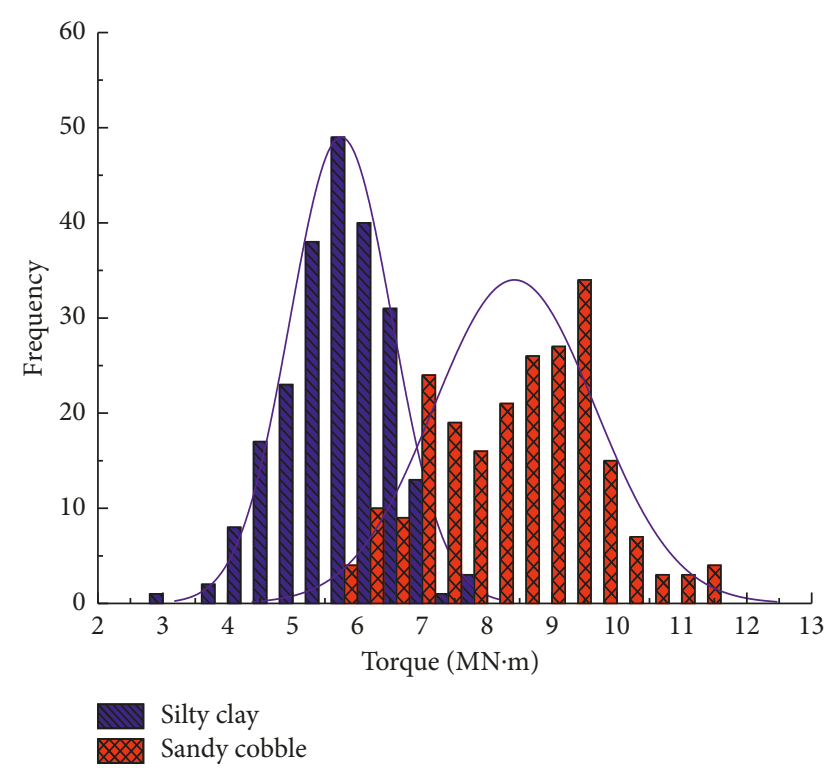

Figure 7: Bar distribution of cutterhead torque.

stable, it can be considered that the increase in the shield thrust is mainly caused by the ground condition change. In the sandy cobble stratum, the shield machine requires a larger shield thrust to overcome various levels of resistance and maintain stable shield tunnelling.

The bar distribution diagram of shield thrust in Figure 9 better illustrates the fluctuation of shield thrust under different geological conditions. The probability distribution curves of the shield thrust under the two geological conditions are similar, and there is not a large difference in the distribution range like the torque probability distribution curves. The standard deviation of the shield thrust in silty clay is $5706 \mathrm{kN}$, while the standard deviation in the sandy cobble stratum is $5791 \mathrm{kN}$, a small difference. Therefore, the shield thrust fluctuation range is basically the same in both geological conditions, and there is a large increase only in the average thrust.

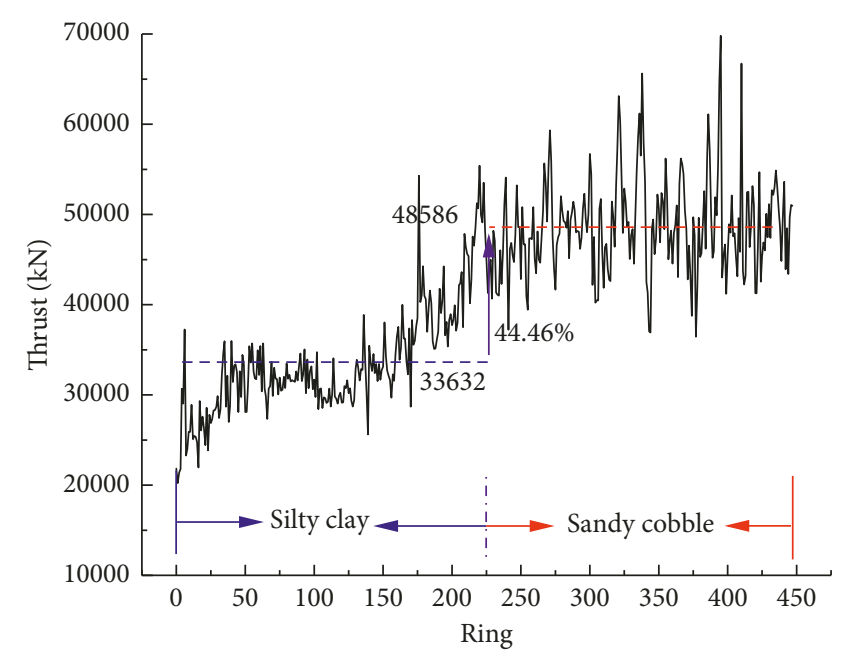

FIGURE 8: History of shield thrust.

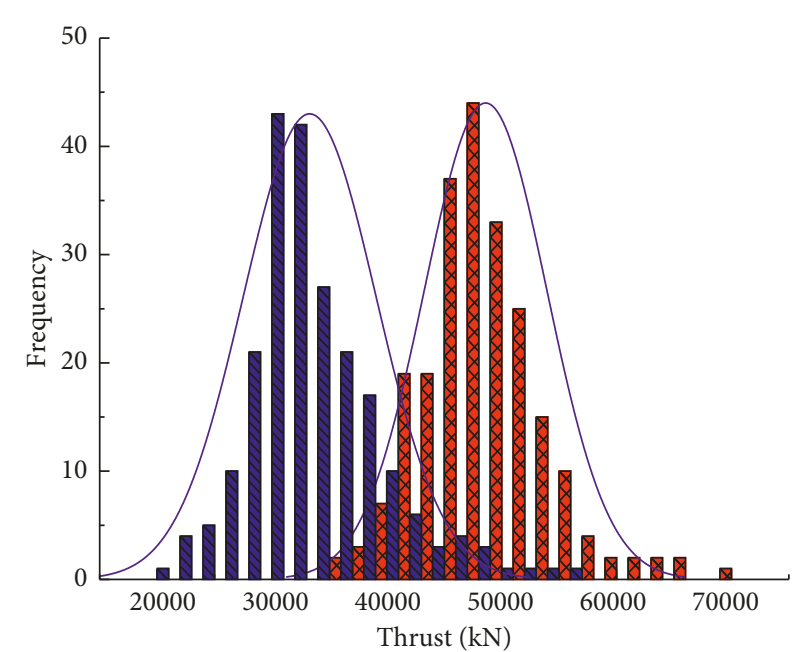

Silty clay

Sandy cobble

FIgURE 9: Bar distribution of shield thrust.

Figure 10 shows the scatter distribution of thrust and torque under different geological conditions. It can be seen from the scatter distribution of the two parameters that when tunnelling in silty clay, the shield thrust and torque are in the left corner. When tunnelling in the sandy cobble stratum, the thrust and torque are greatly increased, the distribution area becomes larger with respect to the silty clay section, and the distribution of the scatter is more extensive, that is, the fluctuation is larger. This is consistent with the torque bar distribution in Figure 7, with a wider range of torque fluctuations.

4.3. Slurry Pressure and Synchronous Grouting Pressure. The setting of slurry pressure is related to whether the shield tunnelling machine can excavate stably on the tunnel face. Figure 11 shows the statistical data of slurry pressure in each ring while shield tunnelling. Slurry pressure is generally 


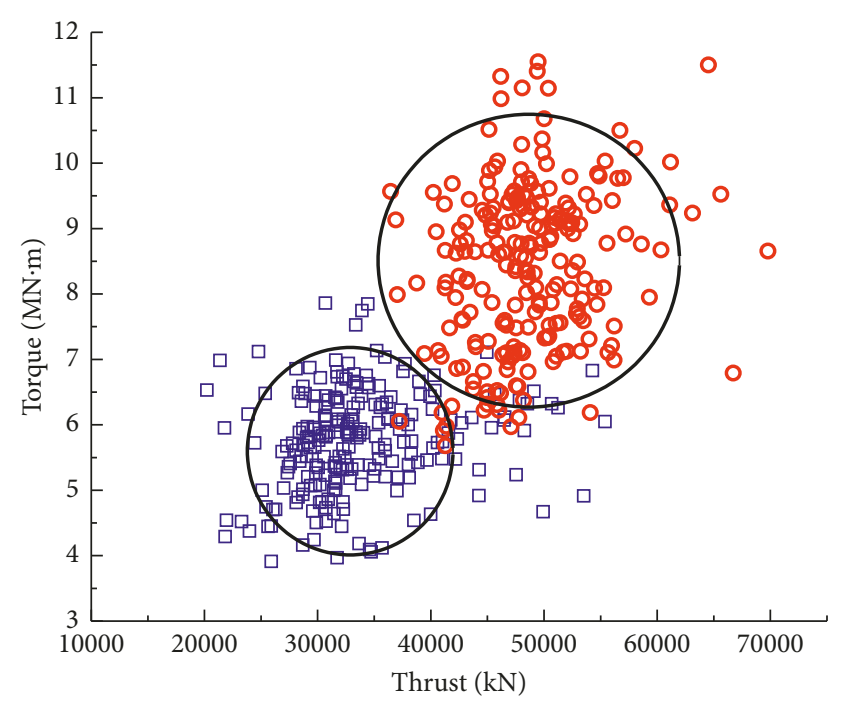

๑ Silty clay

o Sandy cobble

Figure 10: Scatter distribution of thrust and torque under two geological conditions.

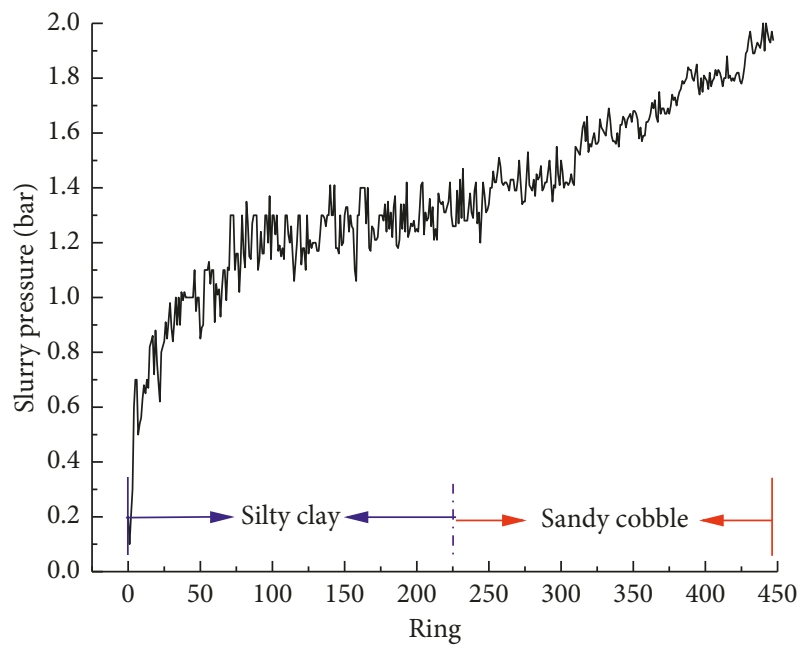

FIgURE 11: History of slurry pressure.

around 0.1 bar 2.0 bar, or about $12.5 \% \sim 23.6 \%$ of the maximum slurry pressure. The slurry pressure in the silty clay stratum is more stable than that in the sandy cobble stratum. In the sandy cobble stratum, the slurry pressure rises continuously, and because the interface of each type of soil is uncertain, the slurry pressure increases continuously. The trend of variation of slurry pressure is up-steady-up, which is closely related to the variation of the cover depth of the tunnel and the strata of the tunnel face. In the two different strata, the synchronous grouting is one of the important means to reduce ground loss and control formation stress, release, and stratum deformation and is an essential process for shield construction. Figure 12 illustrates the history of synchronous grouting pressure. Grouting pressure is generally around 3.5 bar $\sim 5.6$ bar, which is set by the field constructor according to the monitoring feedback.

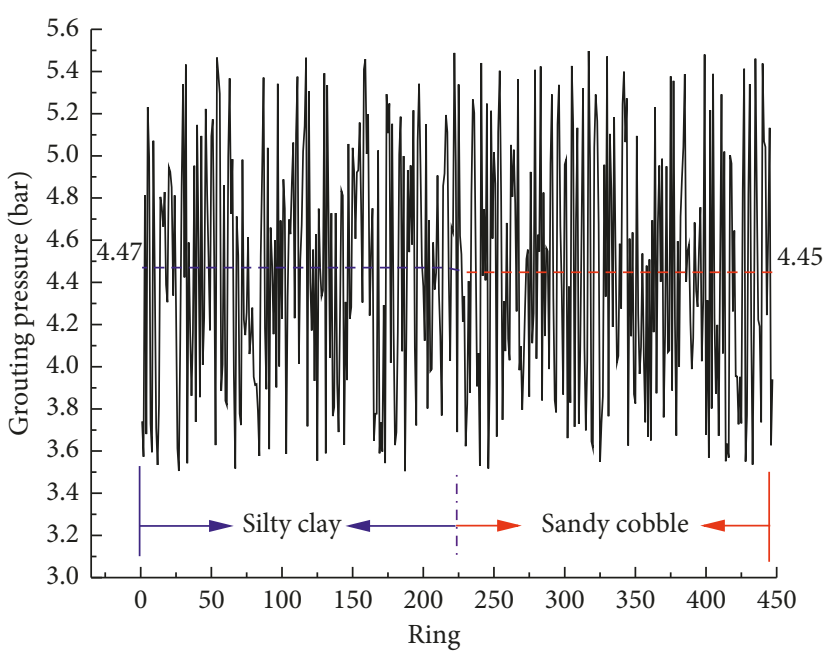

FIgURE 12: History of synchronous grouting pressure.

The change of grouting pressure is relatively stable, with no significant ups or downs. Both the slurry pressure and the synchronous grouting pressure are applied to the numerical model for better simulation in the following numerical simulation.

When comparing the key parameters of shield tunnelling in silty clay and sandy cobble stratum, it can be seen that the cutterhead rotational speed remains at a relatively stable level and the tunnelling speed is reduced by a small extent, while the shield thrust and the cutterhead torque increase greatly. The reason is that the resistance is relatively greater during tunnelling in the sandy cobble stratum and the pebbles in the strata will seriously affect the tunnelling efficiency of the shield machine. However, in order to guarantee the construction period and maintain the tunnelling speed in the silty clay, it is necessary to greatly increase the shield thrust and the cutterhead torque to ensure that the shield machine can smoothly penetrate the sandy cobble stratum with a lot of pebbles. This also illustrates the large changes in shield thrust and cutter torque due to the formation changes while shield tunnelling.

\section{Surface Settlement}

5.1. Surface Settlement Monitoring On-Site. Ground loss was first proposed by Peck [37]. Peck pointed out that surface settlement trough volume is equal to ground loss, and ground loss can be calculated in reverse according to the volume of the surface settlement trough. However, the settlement caused by drainage consolidation is not taken into account in this method. In fact, ground loss consists of two parts: the loss caused by the shield tunnelling, which is the undrained loss, and the ground loss due to soil consolidation and creep. There are no rivers or lakes in the tunnel area, so the groundwater is not developed. In light of existing similar projects in Beijing, it can be considered that the ground loss caused by drainage consolidation settlement is not included in the total ground loss. 
Therefore, in this study, it is assumed that the ground loss is only caused by shield tunnelling.

Important structures along the tunnel are densely distributed, with many underground pipelines and the parallel metro line 13 , so the observation of surface settlement during shield construction is particularly important. Due to the density and complexity of the surface structures above the tunnel, appropriate settlement monitoring sections will be set up according to the ground conditions. Based on the cover depth and formation of the tunnel, $20 \mathrm{~m}$ is determined as the settlement monitoring range. Along the surface of the tunnel axis, settlement monitoring points are set every $10 \mathrm{~m}$. Some of these sections and points are illustrated in Figure 13.

The surface settlement caused by tunnel excavation is generally similar to the Gaussian curve; that is, the maximum surface settlement is directly above the tunnel axis [35]. Figure 14 shows the maximum surface settlement directly above the tunnel axis. It can be seen that the maximum settlement $\left(S_{v, \max }\right)$ is lower than $25 \mathrm{~mm}$, with an average value of about $10.785 \mathrm{~mm}$. As can be seen in Figure 14, the surface settlement is well controlled due to the stratum reinforcement in the launching section of the shield. After the shield tunnelling through the reinforcement area, the peak value of surface settlement appears. Since the elastic modulus of silty clay is smaller than that of the sandy cobble stratum, and the cover depth is relatively shallow, the peak value occurs in the silty clay section. In the subsequent shield tunnelling, since the shield tunnel undercrossing important buildings and areas, the corresponding strata are also strengthened, and the surface settlement is effectively controlled. The maximum surface settlement fluctuates greatly in the silty clay stratum, while the maximum surface settlement is relatively stable in the sandy cobble stratum, demonstrating good excavation control during tunnelling.

\subsection{Computational Modelling}

5.2.1. Finite Difference Model. In order to study the ground deformation during slurry shield tunnelling from sandy clay to sandy cobble stratum, two refined 3D finite difference (FD) models were developed using FLAC3D, setting monitoring sections at DK17 +885 and DK17 +400 , respectively. Considering the actual tunnel size and the Saint-Venant principle, the sizes of the two models were $70 \mathrm{~m} \times 100 \mathrm{~m} \times 75 \mathrm{~m}$ at DK17 +885 and $70 \mathrm{~m} \times 100 \mathrm{~m} \times 80 \mathrm{~m}$ at DK17 +400 . Due to the symmetry of the model, only half-FD models were developed (Figure 15) with zero transverse ( $x$-axis) displacement at $x=0$ and $x=70 \mathrm{~m}$ and zero longitudinal ( $y$-axis) displacement at $y=0 \mathrm{~m}$ and $y=100 \mathrm{~m}$. The top model boundary $(z=75 \mathrm{~m}$ and $z=80 \mathrm{~m})$ was set to be free, and the vertical movement at the bottom boundary $(z=0)$ was fixed. For this model, the physical and mechanical properties of the stratum determined from the geotechnical data report are provided in Table 1. The soil was modelled using solid elements with 8-grid points. A linear elastic, perfectly plastic Mohr-Coulomb constitutive model was employed with nonassociative flow.

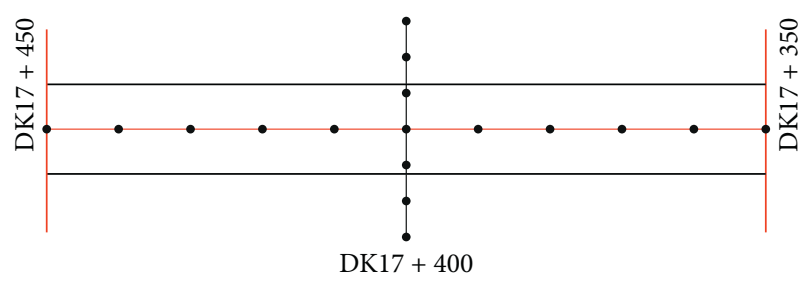

FIgURE 13: Monitoring sections and points from DK17 +350 to $\mathrm{DK} 17+450$.

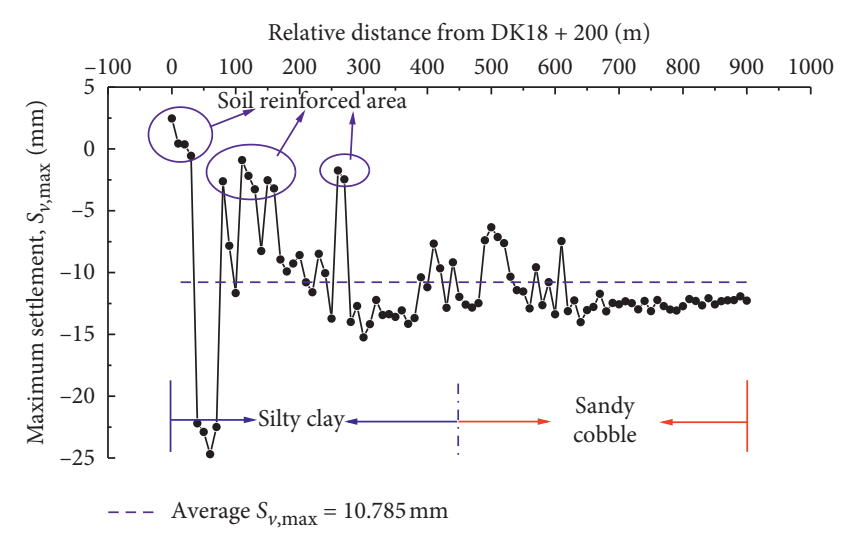

FIgURE 14: Maximum settlement of all monitoring points and average values.

The cover depths from the surface to the center of the tunnel are $18.32 \mathrm{~m}$ and $23.32 \mathrm{~m}$, and the thickness of the strata layer at different monitoring section is shown in Table 2. In summary, the 3D soil-tunnel model consists of 346,000 zones and 359,661 grid points at DK17 +885 and 535,000 zones and 553,278 grid points at $\mathrm{DK} 17+400$.

In the refined FD models, the shield machine, backfill grout, and lining were considered to simulate the shield tunnelling. The details of the tunnel structure geometries and material properties are provided in Table 3. It is worth noting that the grouting layer is divided into three levels for hardening which is similar to the simulation method in the papers by Thomas and Günther [38], Lambrughi et al. [39], and Kavvadas et al. [40] and then Young's modulus is divided into three levels (Table 3). A linear elastic constitutive model was employed for the tunnel structure. For refined simulation, the setting of slurry pressure and grouting pressure is particularly important in determining the influence of surface settlement. Therefore, the parameters of slurry pressure and grouting pressure from on-site monitoring (illustrated in Figures 11 and 12, respectively) were applied in the model. It should be noted that the slurry pressure and grouting pressure were applied in the model by taking the average values from the previous numerical simulations, while in this study, the parameter values of each ring (which are not fixed values) were applied in the model in each step. The slurry pressure was applied on the tunnelling face, and the grouting pressure was applied radially on the excavated soil face (around the tunnel annulus) within only one ring after the shield machine. The thrust reaction was also applied radially on the lining ring after the 

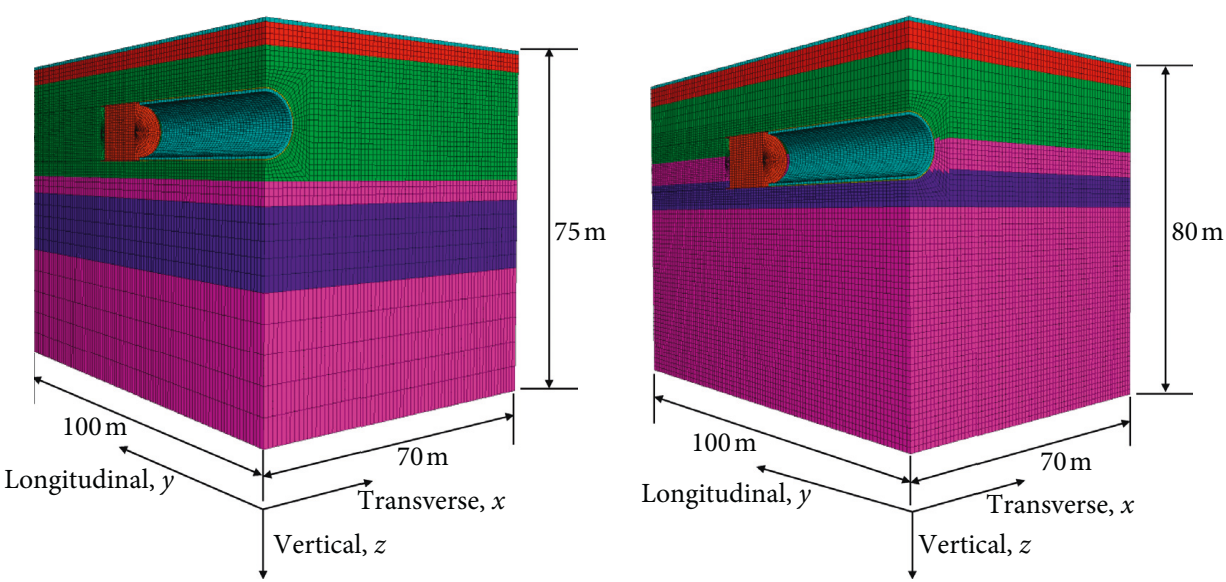

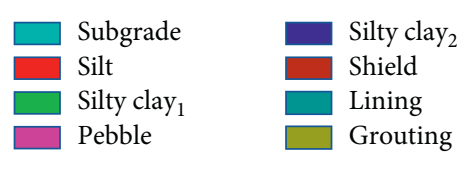

(a)

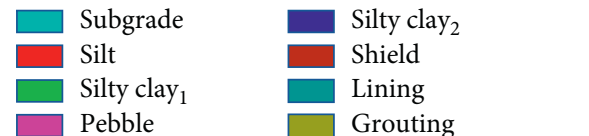

(b)

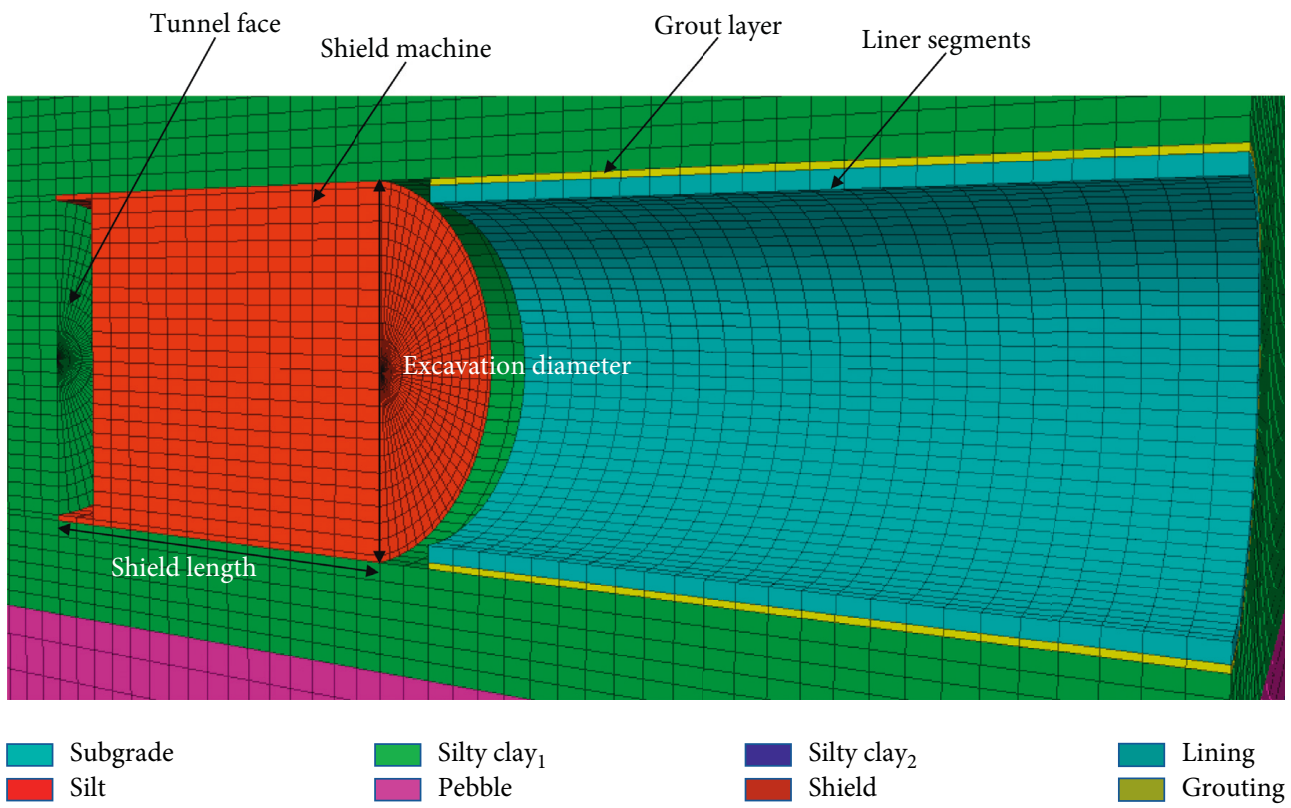

(c)

FIGURE 15: Three-dimensional model of slurry shield TBM tunnelling: (a) 3D overview for DK17 + 885; (b) 3D overview for DK17 + 400; (c) discretization of the model.

TABLE 1: Physical and mechanical properties of the stratum.

\begin{tabular}{|c|c|c|c|c|c|}
\hline Strata layer & Bulk density $\left(\mathrm{kN} / \mathrm{m}^{3}\right)$ & Young's modulus (MPa) & Poisson's ratio & Friction angle $\left({ }^{\circ}\right)$ & Cohesion $(\mathrm{kPa})$ \\
\hline Pavement & 25 & 1366 & 0.3 & & \\
\hline Silt & 20.1 & 41.25 & 0.3 & 25.2 & 24.3 \\
\hline 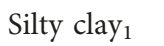 & 19.9 & 37 & 0.3 & 18.4 & 33.8 \\
\hline Pebble soil ${ }_{1}$ & 20.2 & 226 & 0.28 & 45 & \\
\hline Silty $_{\text {clay }_{2}}$ & 20 & 38 & 0.3 & 19.6 & 36 \\
\hline Pebble soil 2 & 20.2 & 226 & 0.28 & 45 & \\
\hline
\end{tabular}

shield machine. While the grout layer and lining were active, the backup train weight was also applied on the lining. The simulation procedure similar to Zhang [36] in FD for the shield tunnelling is shown in Figure 16. It should be specifically stated that for the numerical modelling of mechanized tunnelling by a shield machine, the presence of water 
TABLE 2: The thickness of the strata layer at different monitoring sections (unit: $\mathrm{m}$ ).

\begin{tabular}{lcc}
\hline \multirow{2}{*}{ Strata layer } & \multicolumn{2}{c}{ Monitoring section } \\
& $\mathrm{DK} 17+885$ & $\mathrm{DK} 17+400$ \\
\hline Pavement & 0.70 & 0.70 \\
Silt & 4.00 & 5.00 \\
Silty clay $_{1}$ & 23.62 & 16.00 \\
Pebble soil $_{1}$ & 4.38 & 6.00 \\
Silty clay $_{2}$ & 15.00 & 6.50 \\
Pebble soil $_{2}$ & 27.30 & 45.80 \\
\hline
\end{tabular}

pressure and consolidation problems are not taken into account in this study.

\subsubsection{Modelling Validation by Simulation Results and Field} Data. The ongoing tunnel excavation was simulated by a step-by-step method depending on the excavation length (excavate $2 \mathrm{~m}$ per step) and construction stages. The models were validated by comparing model deformation results to the measured field data. The field data include surface settlement directly above the tunnel profile recorded by the construction site at one monitoring point $(x=0, y=50)$ during tunnel excavation. In Figure 17, the horizontal axis denotes the distance from the TBM face to the monitoring section while shield tunnelling. Both of the simulation results show a settlement trend that is generally consistent with the field data; the final settlement values of the numerical simulation are slightly larger than the final settlement values obtained by monitoring, so the simulation results could be considered safe. The surface settlement values obtained from the field data are larger than the simulation data at $\mathrm{DK} 17+885$ but smaller than simulation data at DK17 +400 . The reason for the difference may be related to the cover depth of the tunnel and the soil properties of the excavation surface.

Figure 18 shows the transverse settlement troughs for simulation models at two different soil strata: DK17 +885 for silty clay and DK $17+400$ for sandy cobble stratum. It can be seen that the settlement troughs are similar to half of a Gaussian curve, although only half of the trough is present. The maximum surface settlement appears above the tunnel axis, and the simulation results are larger than the field data. The settlement of the soil away from the axis gradually decreases, and the tendency of the upper arch appears. The affected region of surface settlement at $\mathrm{DK} 17+400$ is larger than that at $\mathrm{DK} 17+885$. The reason for this difference is related to the strata formation and cover depth.

The settlement law obtained by numerical calculation is basically consistent with the monitoring results, but the difference still exists because numerical simulation could not fully simulate the actual construction of the shield tunnelling. There are some assumptions in the simulation, and only the important influencing factors are considered and analyzed, which will inevitably cause some differences. And in the numerical simulation, each excavation step is calculated to be balanced, which can analyze the influence of the excavation step, but it is difficult to consider the influence of time. In the actual excavation process, the settlement of the measured point still has the trend of development due to the incomplete consolidation of soil and the incomplete release of excess pore water pressure. The numerical model in this paper can reflect the ground disturbance induced by large diameter slurry shield tunnelling in two different strata. The results verify that the simulation model can reasonably match the observed deformation.

\subsection{Simulation Results and Discussion}

5.3.1. Surface Settlement Rates. Three cases were selected to correspond with the field data: the cutter before the monitoring sections, the shield through the monitoring sections, and the shield tail after the monitoring sections. The surface settlement curves of DK17 +885 and DK17 +400 are shown in Figure 19. While shield tunnelling in the silty clay stratum and sandy cobble stratum, similar settlement characteristics are obtained. The settlement troughs are similar to a Gaussian curve and deform narrowly in the lower strata and expand in the upper strata. The uplift value increases while shield tunnelling, and it is very small before and at the monitoring sections. Uplift in DK17 +400 is much smaller than that in DK17 +885 , and this is due to the huge Young's modulus of $226 \mathrm{MPa}$ in sandy cobble soil, while in the silty clay soil, it is only $37 \mathrm{MPa}$. The larger Young's modulus means that the corresponding deformation displacement will be relatively small. The affected region in sandy cobble soil of surface settlement caused by shield tunnelling is larger than that in silty clay soil.

5.3.2. Parametric Analysis. A series of parametric analyses were performed using the calibrated FD model to characterize the influence of slurry pressure and grouting pressure on surface settlement. Figure 20 shows the transverse settlement curve of the monitoring section $\mathrm{DK} 17+400$ under different grouting pressures, where $P_{\mathrm{G}}$ represents the average grouting pressure. From Figure 20, as the grouting pressure increases from $0.5 P_{\mathrm{G}}$ to $2.0 P_{\mathrm{G}}$, the maximum surface settlement increases from $-20.61 \mathrm{~mm}$ to $-11.10 \mathrm{~mm}$, the change rate is from fast to slow, and the width of settlement curves is basically the same. With the increase of grouting pressure, the uplift at the arch shoulder increases gradually. When $2.0 P_{\mathrm{G}}$ is applied to the model, the uplift at the arch shoulder is more serious, which is harmful to segment lining and ground buildings. Shield tunnelling will cause disturbance to the soil, plus the effect of over-excavation, and the grouting pressure is too small to ensure that the slurry is fully filled with the shield tail gap, while excessive grouting pressure may damage the segment lining. The surface settlement could be effectively controlled by adjusting the grouting pressure. It is suggested that the range of grouting pressure should be $1.0 \sim 1.5 P_{\mathrm{G}}$. 
TABLE 3: Summary of lining, grout, and shield machine properties.

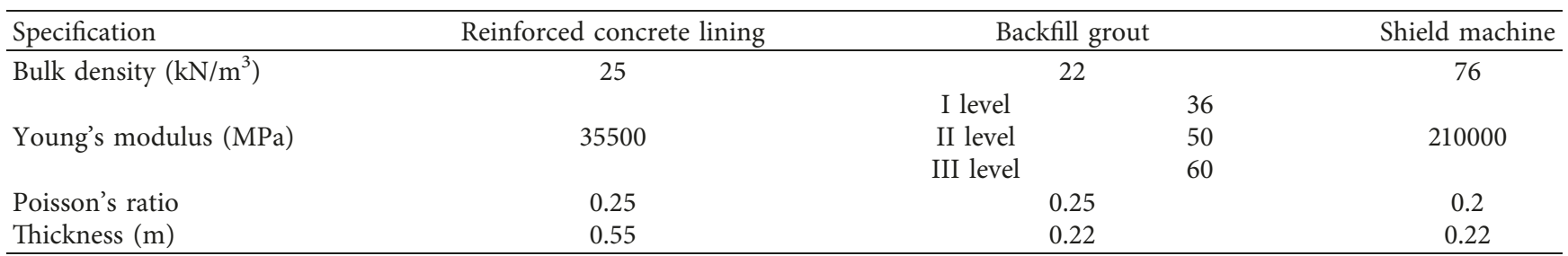

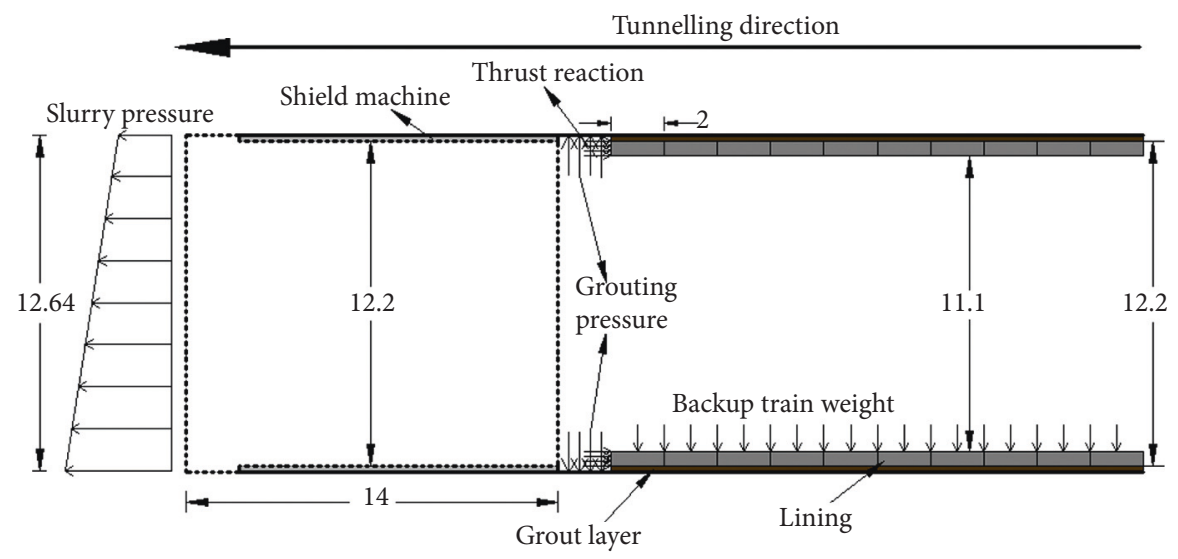

FIGURE 16: Simulation procedure in FD for shield tunnelling (unit: $\mathrm{m}$ ).

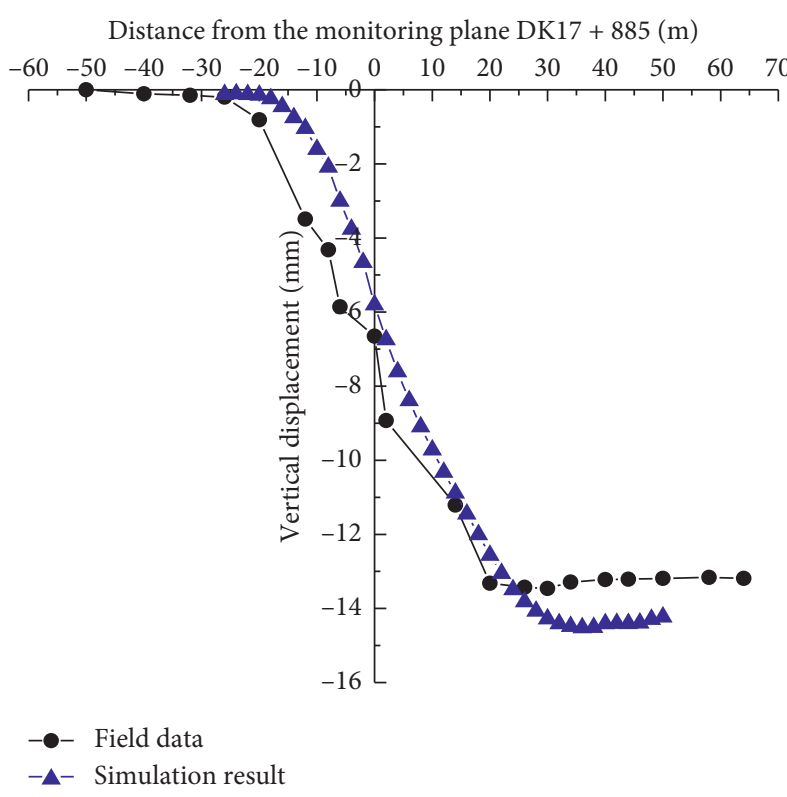

(a)

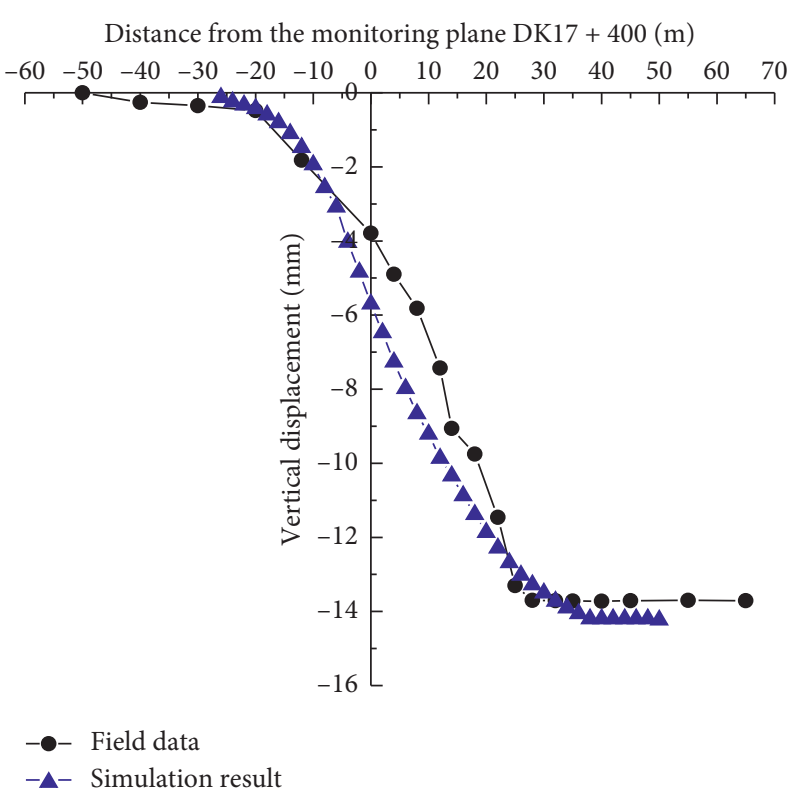

(b)

FIgURE 17: Longitudinal settlement comparison between simulation results and field data: (a) DK17 + 885; (b) DK17 + 400.

Figure 21 shows the transverse settlement curve of the monitoring section DK17+400 under different slurry pressures, where $P_{\mathrm{S}}$ represents the average slurry pressure. As the slurry pressure increases from $0.5 P_{\mathrm{S}}$ to $2.0 P_{\mathrm{S}}$, the maximum surface settlement increases from $-16.01 \mathrm{~mm}$ to $-14.50 \mathrm{~mm}$. When the slurry pressure is less than $P_{\mathrm{S}}$, the absolute value of surface settlement increases, while the slurry pressure is greater than $1.0 P_{\mathrm{S}}$, the change of surface settlement is not obvious, and the width of settlement trough is basically the same, which is obviously different from the change of grouting pressure. Because the monitoring section DK17 + 400 is mainly sandy cobble soil, the 


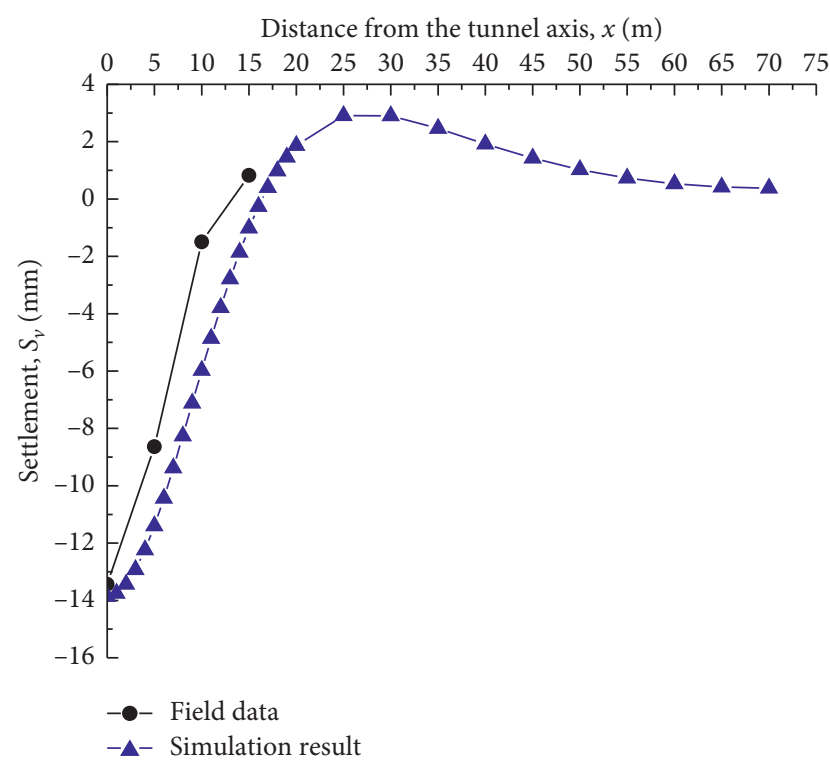

(a)

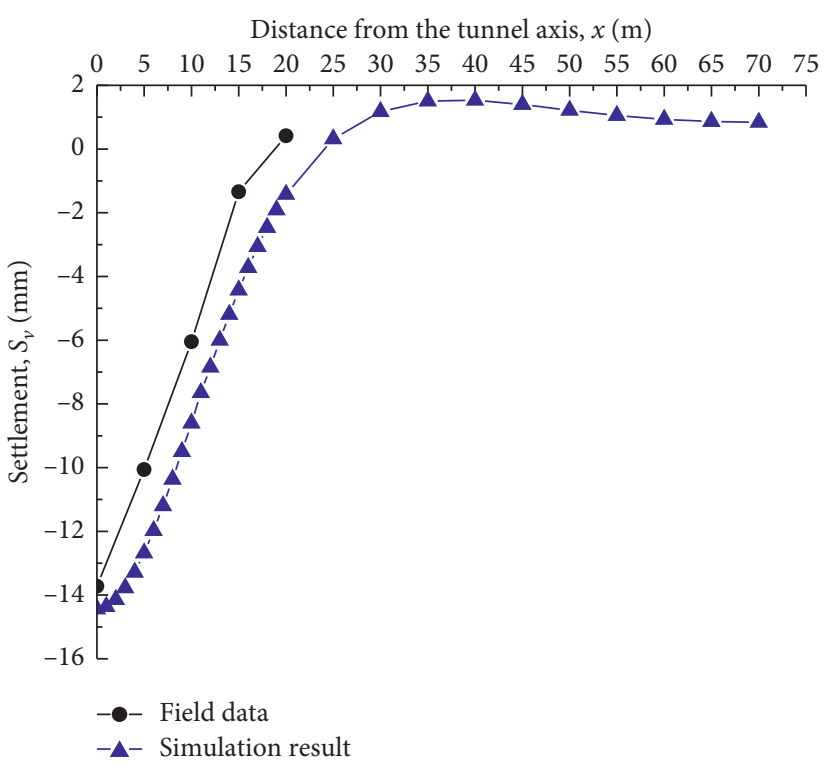

(b)

FigURE 18: Surface settlement troughs comparison between simulation results and field data: (a) DK17 + 885; (b) DK17 + 400.

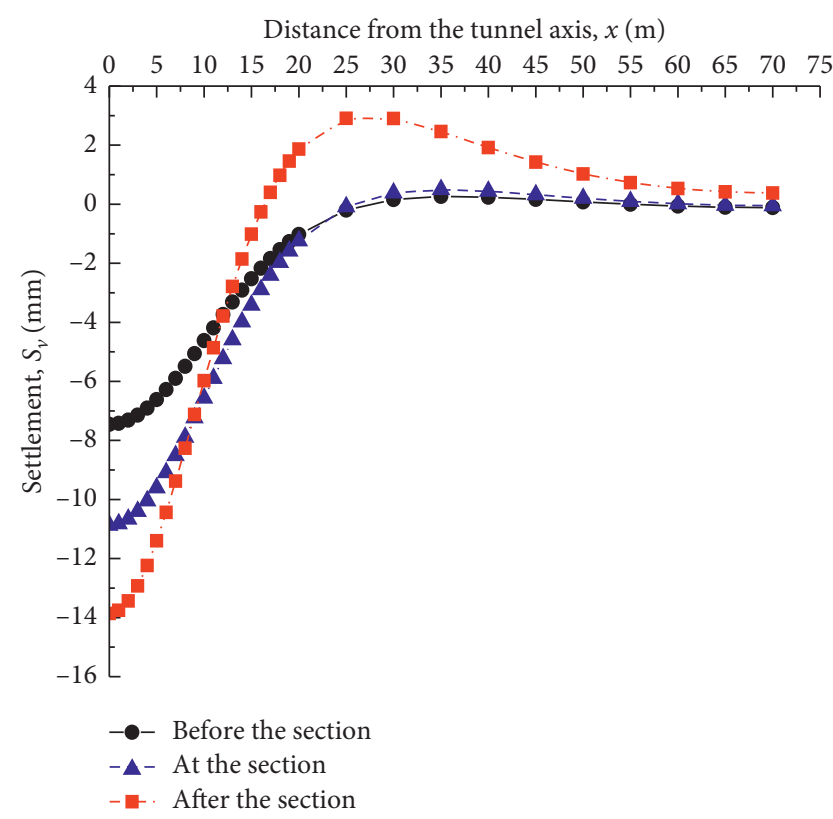

(a)

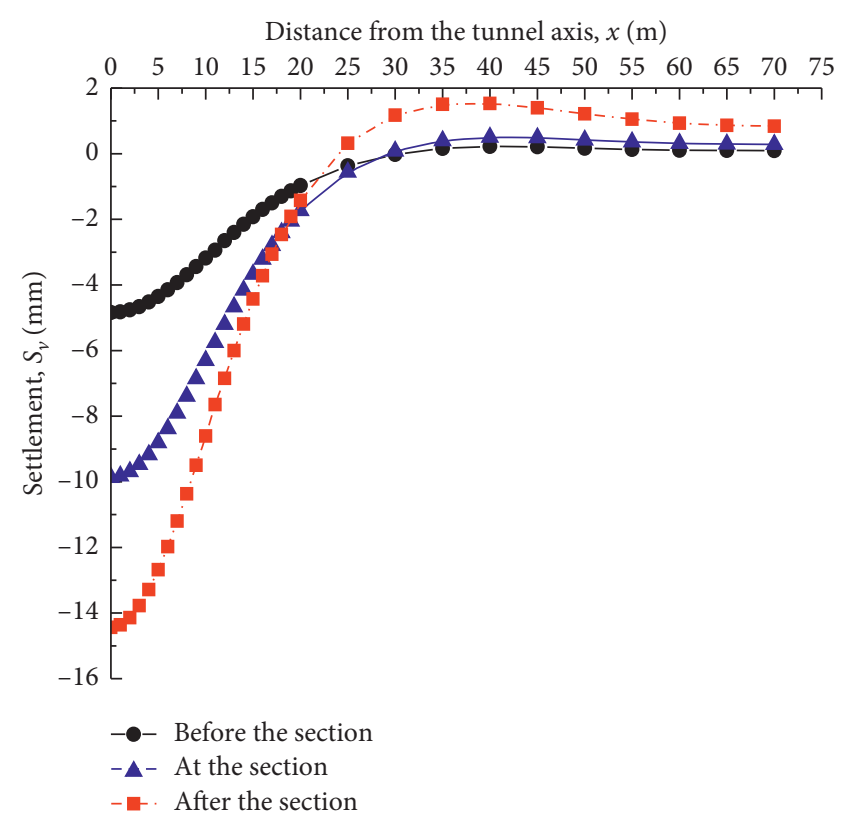

(b)

FIgURE 19: Surface settlement troughs at various stages: (a) DK17 + 885; (b) DK17 + 400 .

soil porosity is relatively high. The increase of slurry pressure only squeezes more slurry into the sandy cobble pore and does not play a role in controlling surface settlement. From the numerical simulation results, surface settlement is closely related to tunnelling key parameters of shield tunnelling. Appropriate adjustment of grouting pressure and slurry pressure can effectively reduce surface settlement, and the influence of grouting pressure on surface settlement is more obvious. Both mud pressure and grouting pressure have a reasonable value. 


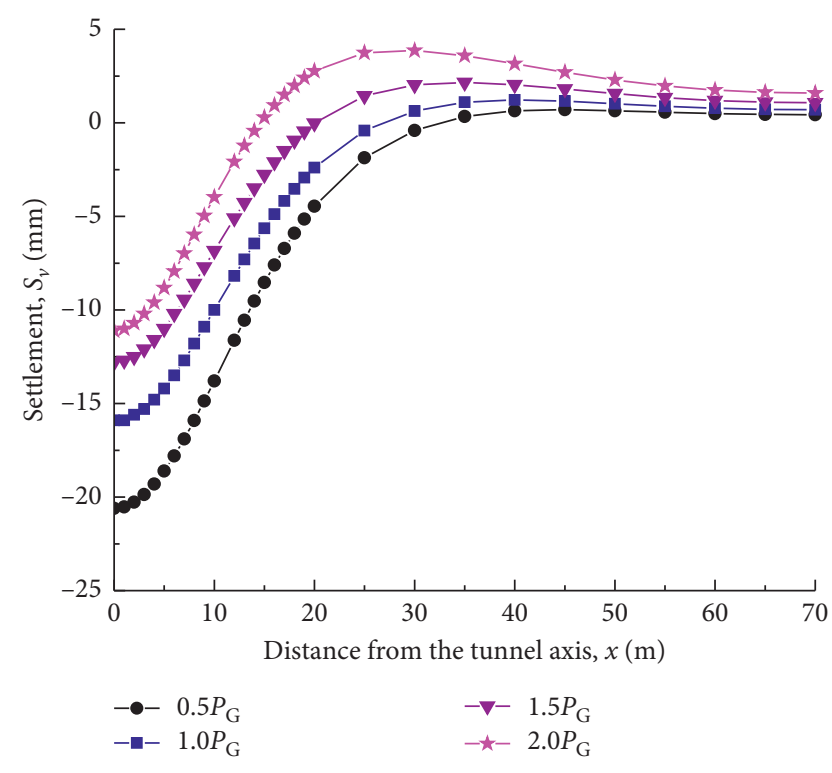

Figure 20: Transverse surface settlement profiles for four different grouting pressures.

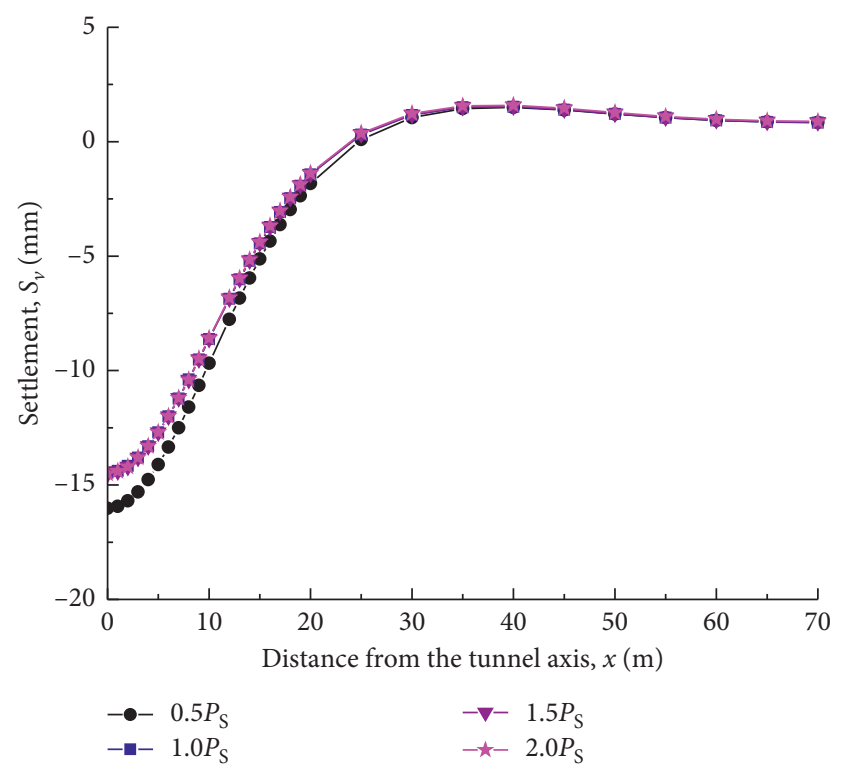

Figure 21: Transverse surface settlement profiles for four different slurry pressures.

\section{Conclusions}

This study presented a case study of the slurry shield tunnel where the strata change from silty clay to sandy cobble stratum. The key parameters and surface settlement were investigated and analyzed using field data and simulation results. 3D refined finite difference models were employed to investigate the ground response during the construction of the large-diameter tunnel. The findings can provide a reference for engineering similar shield tunnels. Based upon the analysis of the field measurements and numerical simulation, the following conclusions can be drawn:
(1) In terms of the change rate of tunnelling parameters, the cutterhead rotational speed remains at a relatively stable level, and the tunnelling speed decreases slightly. However, due to the change of geological conditions, both the shield torque and thrust increase greatly. In the sandy cobble stratum, the torque during shield tunnelling increased by $46.43 \%$ compared with that of silty clay, while the thrust increased by $44.46 \%$. As the content of pebbles increases significantly in the sandy cobble stratum, the force required for the shield machine to propel is larger than in silty clay, resulting in an increase in torque.

(2) The scatter distribution of thrust and torque is different for shield tunnelling in two different geological conditions; specifically, it is more discrete in the sandy cobble stratum. The analysis of the probability distribution of the torques and thrusts of the shield shows that the discrete distribution is mainly caused by the fluctuation of torques, rather than the fluctuation of thrust. The cause of the larger torque fluctuation range is the complexity and changeability of the sandy cobble stratum, with different pebbles, particle sizes, and distribution locations in two adjacent rings.

(3) The FLAC3D models were calibrated and validated using data from the Tsinghuayuan tunnel project where surface settlement was observed. For refined simulation, key parameters from the measurement data were applied to the models. The refined model has good performance in terms of the accuracy and efficiency for tunnelling simulation. The affected region of surface settlement in the sandy cobble stratum is larger than that in the silty clay stratum. The settlement troughs are similar to a Gaussian curve, deforming narrowly in the lower strata and expanding in the upper strata. Most of the surface settlement was caused before the monitoring section in the silty clay stratum, while most of the surface settlement was caused when shield cutterhead through the monitoring section in the sandy cobble stratum.

(4) Appropriate adjustment of grouting pressure and slurry pressure can effectively reduce surface settlement, and the influence of grouting pressure on surface settlement is more obvious. Both mud pressure and grouting pressure have a reasonable value. In the future excavations in similar complex strata using a slurry shield, immediate responses to changes in the terrain are recommended in order to ensure construction efficiency. This study provides a good reference for slurry TBM tunnelling in two successive different strata.

\section{Data Availability}

The data used to support the findings of this study are available from the corresponding author upon request. 


\section{Conflicts of Interest}

The authors declare no conflicts of interest.

\section{Acknowledgments}

This research was funded by the China Railway Corporation Science and Technology Research and Development Program (grant no. 2017G007-B), the National Natural Science Foundation of China (grant no. 51578460), the National Key Research and Development Plan Sub-Topic (grant no. 2016YFC0802205-8), and the Key Research and Development Program of Sichuan Science and Technology Plan (grant no. 2017SZ0043). We are thankful to the China Railway 14th Bureau Group Big Shield Engineering Co. Ltd for sharing the data.

\section{References}

[1] C. He, K. Feng, and Y. Fang, "Review and prospects on constructing technologies of metro tunnels using shield tunnelling method," Journal of Southwest Jiaotong University, vol. 50, no. 1, pp. 97-109, 2015, in Chinese.

[2] W.-I. Chou and A. Bobet, "Predictions of ground deformations in shallow tunnels in clay," Tunnelling and Underground Space Technology, vol. 17, no. 1, pp. 3-19, 2002.

[3] C. He, K. Feng, Y. Fang, and Y.-C. Jiang, "Surface settlement caused by twin-parallel shield tunnelling in sandy cobble strata," Journal of Zhejiang University SCIENCE A, vol. 13, no. 11, pp. 858-869, 2012.

[4] C.-G. Lin, Z.-M. Zhang, S.-M. Wu, and F. Yu, "Key techniques and important issues for slurry shield under-passing embankments: a case study of Hangzhou Qiantang River Tunnel," Tunnelling and Underground Space Technology, vol. 38, pp. 306-325, 2013.

[5] Y. Fang, Z. Yang, G. Cui, and C. He, "Prediction of surface settlement process based on model shield tunnel driving test," Arabian Journal of Geosciences, vol. 8, no. 10, pp. 7787-7796, 2015.

[6] H. S. Sun, L. W. Wang, S. W. Chen, H. Deng, and J. Zhang, "A precise prediction of tunnel deformation caused by circular foundation pit excavation," Applied Science, vol. 9, no. 11, pp. 1-12, 2019.

[7] A. R. Selby, "Tunnelling in soils-ground movements and damage to buildings in Workington, UK," Geotechnical and Geological Engineering, vol. 17, no. 3/4, pp. 351-371, 1999.

[8] J. N. Shirlaw, J. C. W. Ong, H. B. Rosser, C. G. Tan, N. H. Osborne, and P. E. Heslop, "Local settlements and sinkholes due to EPB tunnelling," Proceedings of the Institution of Civil Engineers-Geotechnical Engineering, vol. 156, no. 4, pp. 193-211, 2003.

[9] V. Guglielmetti, P. Grasso, A. Mahtab et al., Mechanized Tunnelling in Urban Areas: Design Methodology and Construction Control, Taylor \& Francis, London, UK, 2008.

[10] R. J. Mair, "Tunnelling and geotechnics: new horizons," Géotechnique, vol. 58, no. 9, pp. 695-736, 2008.

[11] S.-M. Liao, J.-H. Liu, R.-L. Wang, and Z.-M. Li, "Shield tunneling and environment protection in Shanghai soft ground," Tunnelling and Underground Space Technology, vol. 24, no. 4, pp. 454-465, 2009.

[12] C. G. Lin, Z. M. Zhang, S. M. Wu et al., "Case study of slurry shield driving parameters' influences on ground surface settlements," China Civil Engineering Journal, vol. 45, no. 4, pp. 116-126, 2012, in Chinese.

[13] G. Zheng, P. Lu, and J. R. Cao, "Risk analysis based on the parameters sensitivity analysis for ground settlement induced by shield tunnelling," Chinese Journal of Rock Mechanics and Engineering, vol. 34, no. S1, pp. 3604-3612, 2015, in Chinese.

[14] C. R. Li, S. H. He, and X. B. Liu, "Study on main parameters control of tunnelling through the yellow river by a slurry balance shield in sandy gravel stratum with some large-size grains," China Civil Engineering Journal, vol. 50, no. S2, pp. 147-152, 2017, in Chinese.

[15] V. Fargnoli, D. Boldini, and A. Amorosi, "TBM tunnellinginduced settlements in coarse-grained soils: the case of the new Milan underground line 5," Tunnelling and Underground Space Technology, vol. 38, pp. 336-347, 2013.

[16] Y. Fang, C. He, A. Nazem, Z. Yao, and J. Grasmick, "Surface settlement prediction for EPB shield tunneling in sandy ground," KSCE Journal of Civil Engineering, vol. 21, no. 7, pp. 2908-2918, 2017.

[17] J. Zhao, Q. M. Gong, and Z. Eisensten, “Tunnelling through a frequently changing and mixed ground: a case history in Singapore," Tunnelling and Underground Space Technology, vol. 22, no. 4, pp. 388-400, 2007.

[18] R. P. Chen, J. Zhu, W. Liu, and X. W. Tang, "Ground movement induced by parallel EPB tunnels in silty soils," Tunnelling and Underground Space Technology, vol. 26, no. 1, pp. 163-171, 2011.

[19] H.-S. Jung, J.-M. Choi, B.-S. Chun, J.-S. Park, and Y.-J. Lee, "Causes of reduction in shield TBM performance - a case study in Seoul," Tunnelling and Underground Space Technology, vol. 26, no. 3, pp. 453-461, 2011.

[20] J. Wongsaroj, F. X. Borghi, K. Soga et al., "Effect of TBM driving parameters on ground surface movements: chanel tunnel rail link contract 220," in Geotechnical Aspects of Underground Construction in Soft Ground, Bakker, Ed., pp. 335-341, Taylor \& Francis Group, London, UK, 2005.

[21] J. Hassanpour, J. Rostami, M. Khamehchiyan, A. Bruland, and H. R. Tavakoli, "TBM performance analysis in pyroclastic rocks: a case history of karaj water conveyance tunnel," Rock Mechanics and Rock Engineering, vol. 43, no. 4, pp. 427-445, 2010.

[22] H. H. Zhu, Q. W. Xu, Q. Z. Zheng et al., "Experimental study on the working parameters of EPB shield tunneling in soft ground," China Civil Engineering Journal, vol. 40, no. 9, pp. 87-94, 2007, in Chinese.

[23] K. Z. Song and M. Sun, "Analysis of influencing factors of shield tunnelling performance in complex rock strata," Chinese Journal of Rock Mechanics and Engineering, vol. 26, no. 10, pp. 2092-2096, 2007, in Chinese.

[24] X. J. Wei, Y. Zhou, and G. Wei, "Research of EPB shield tunnelling parameter relations and their influence on stratum dispalmen," Rock and Soil Mechanics, vol. 34, no. 1, pp. 73-78, 2013, in Chinese.

[25] E. Eberhardt, "Numerical modelling of three-dimension stress rotation ahead of an advancing tunnel face," International Journal of Rock Mechanics and Mining Sciences, vol. 38, no. 4, pp. 499-518, 2001.

[26] Z. X. Zhang, X. Y. Hu, and K. D. Scott, "A discrete numerical approach for modeling face stability in slurry shield tunnelling in soft soils," Computers and Geotechnics, vol. 38, no. 1, pp. 94-104, 2011.

[27] K. Zhao, M. Janutolo, and G. Barla, "A completely 3D model for the simulation of mechanized tunnel excavation," Rock 
Mechanics and Rock Engineering, vol. 45, no. 4, pp. 475-497, 2012.

[28] K. A. Valizadeh, M. H. Sadaghiani, and M. M. Ahmadi, "Numerical modelling of ground settlement control of large span underground metro station in Tehran Metro using Central Beam Column (CBC) structure," Tunnelling and Underground Space Technology, vol. 28, pp. 1-9, 2012.

[29] N.-A. Do, D. Dias, P. Oreste, and I. Djeran-Maigre, "Threedimensional numerical simulation of a mechanized twin tunnels in soft ground," Tunnelling and Underground Space Technology, vol. 42, pp. 40-51, 2014.

[30] V. Fargnoli, C. G. Gragnano, D. Boldini, and A. Amorosi, "3D numerical modelling of soil-structure interaction during EPB tunnelling," Géotechnique, vol. 65, no. 1, pp. 23-37, 2015.

[31] A. M. Michael, G. Jacob, K. Bernadette, and Y. Fang, "The role of slurry TBM parameters on ground deformation: field results and computational modelling," Tunnelling and Underground Space Technology, vol. 57, pp. 257-264, 2016.

[32] P. Li, H. Liu, Y. Zhao, and Z. Li, "A bottom-to-up drainage and water pressure reduction system for railway tunnels," Tunnelling and Underground Space Technology, vol. 81, pp. 296-305, 2018.

[33] J. Lai, K. Wang, J. Qiu, F. Niu, J. Wang, and J. Chen, "Vibration response characteristics of the cross tunnel structure," Shock and Vibration, vol. 2016, Article ID 9524206, 16 pages, 2016.

[34] H. Rohola, R. Jamal, and U. Rahtiyar, "3D finite difference model for simulation of double shield TBM tunnelling in squeezing grounds," Tunnelling and Underground Space Technology, vol. 40, pp. 109-126, 2014.

[35] C. Liu, Z. Zhang, and R. A. Regueiro, "Pile and pile group response to tunnelling using a large diameter slurry shield-case study in Shanghai," Computers and Geotechnics, vol. 59, pp. 21-43, 2014.

[36] Z. X. Zhang, C. Liu, X. Huang, C. Y. Kwok, and L. Teng, "Three-dimensional finite-element analysis on ground responses during twin-tunnel construction using the URUP method," Tunnelling and Underground Space Technology, vol. 58, pp. 133-146, 2016.

[37] R. B. Peck, "Deep excavation and tunnelling in soft ground," in Proceedings of the 7th International Conference on Soil Mechanics and Foundation Engineering, pp. 225-290, Mexico City, Mexico, 1969.

[38] K. Thomas and M. Günther, "A 3D finite element simulation model for TBM tunnelling in soft ground," International Journal for Numerical and Analytical Methods in Geomechanics, vol. 28, no. 14, pp. 1441-1460, 2004.

[39] A. Lambrughi, L. Medina Rodríguez, and R. Castellanza, "Development and validation of a 3D numerical model for TBM-EPB mechanised excavations," Computers and Geotechnics, vol. 40, pp. 97-113, 2012.

[40] M. Kavvadas, D. Litsas, I. Vazaios, and P. Fortsakis, "Development of a 3D finite element model for shield EPB tunnelling," Tunnelling and Underground Space Technology, vol. 65, pp. 22-34, 2017. 


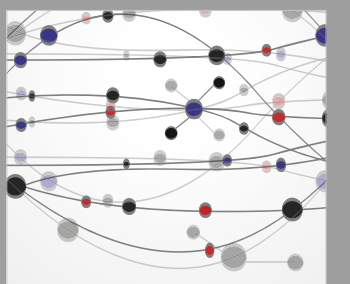

The Scientific World Journal
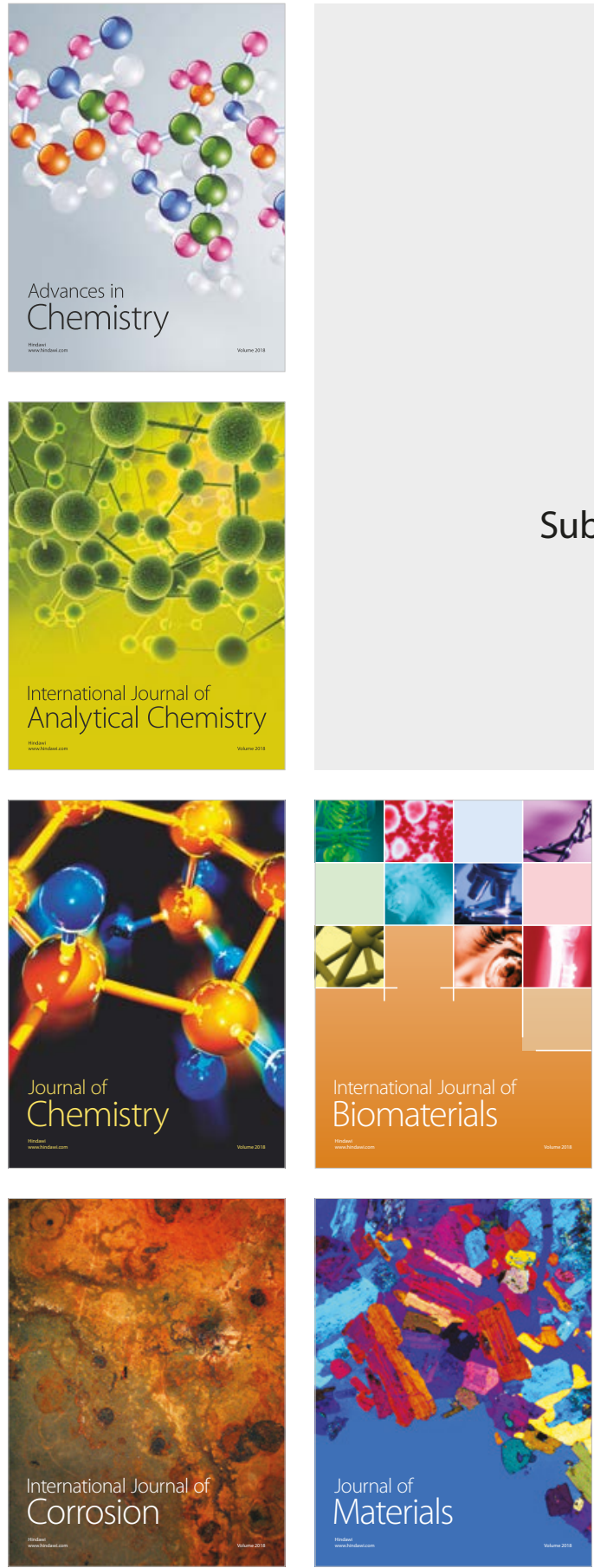

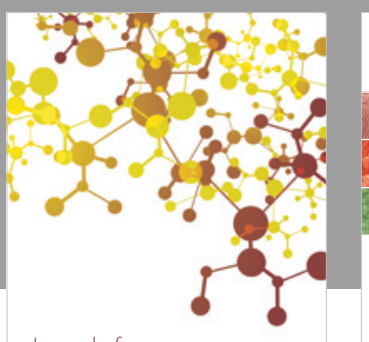

Journal of

Applied Chemistry
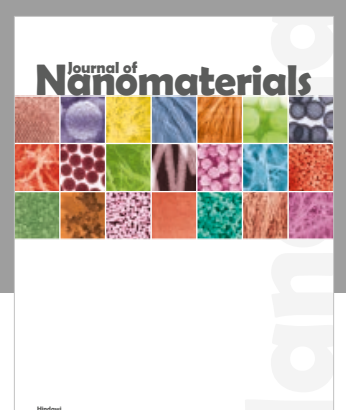

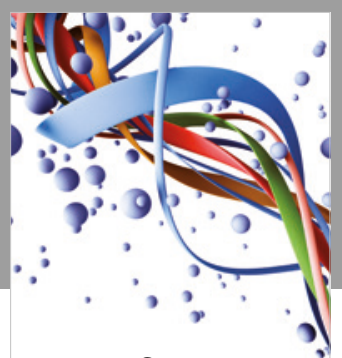

Scientifica

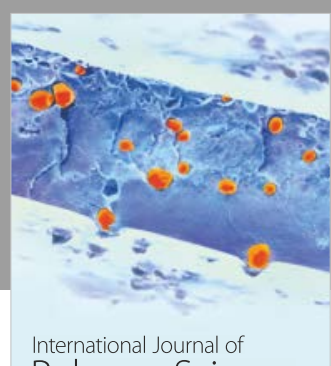

Polymer Science

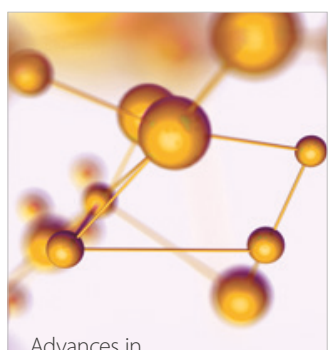

Physical Chemistry
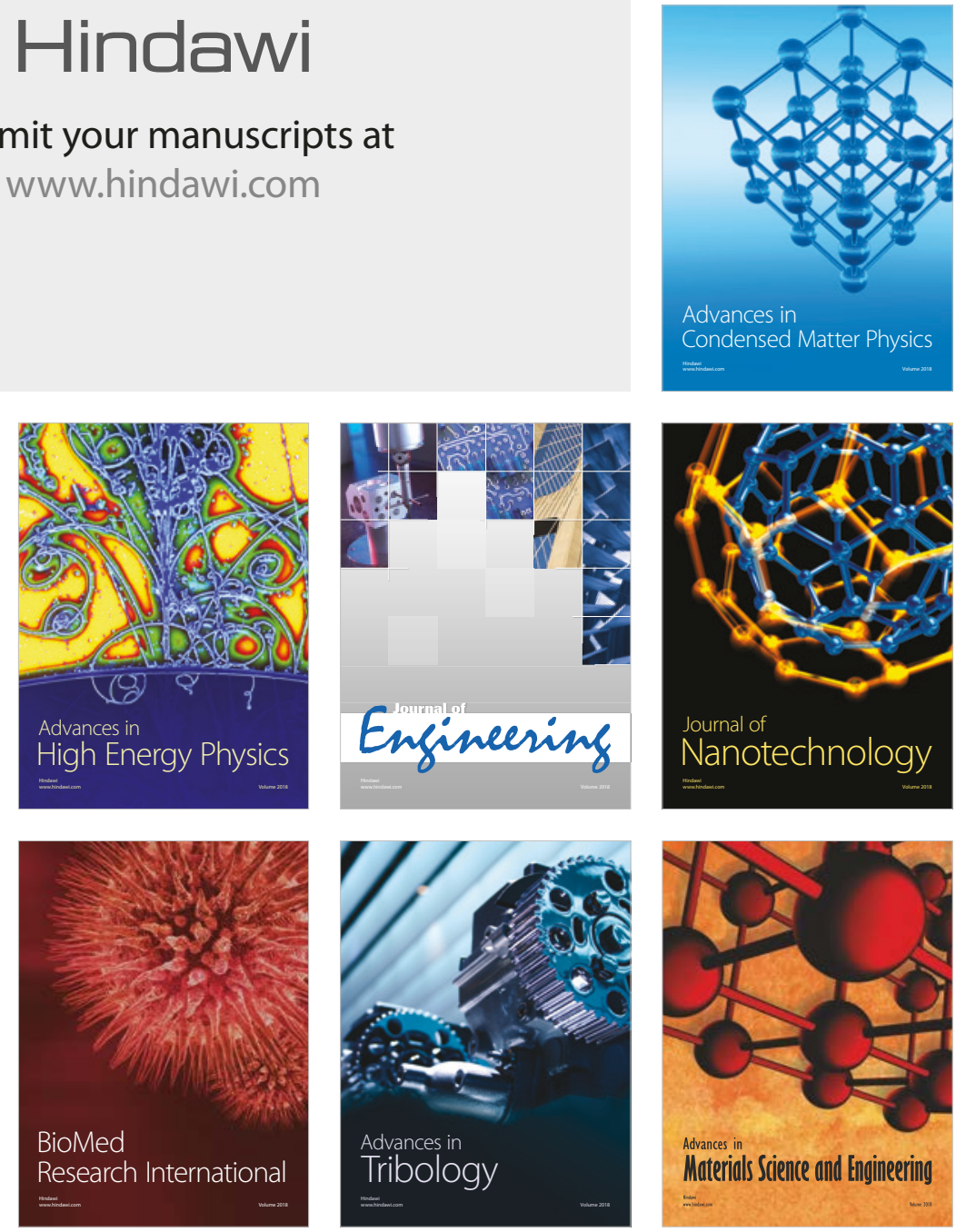